good we could be doing if we didn't have to treat victims of violence."

"There are 2 stories in the north," says Strother. "There is Karamoja with the cattle-raiding and then there is the rest of Northern Uganda where the LRA conflict took place."

Those 2 regions tell 2 different stories of health care as well: I, in Karamoja, of a health care system that has to find a way to work amidst chronic violence, and another, in the rest of the north, of a health care system that has its fingers crossed that in a few years it can operate with some semblance of normalcy in an environment free of violence. - Christopher Mason, Lira, Uganda

\section{Delivering health care on}

\section{US\$19 per capita}

$\mathrm{W}$ alking through the corridors of Uganda's largest hospital, Mulago, in Kampala, it is clear that standard yardsticks used to measure a country's health care system do not tell the full story.

Spending figures and patient wait times do not explain how a health care system functions when its largest, and best equipped, hospital's maternity ward is so full that women frequently give birth on the floor - this being the case when, to begin with, only $13 \%$ of the country's mothers give birth in a hospital.

By Western standards, the system is almost unfathomable. Without access to equipment and technology typically found in hospitals throughout Europe and North America, the diagnosis is largely symptom driven. Doctors and medical students must rely on decadesold textbooks for medical knowledge.

That they are able to achieve any measure of success, in a country that is I of the world's poorest and has an extremely dispersed population, is often a testimony to their ingenuity and to the substantial financial support provided by the international community, which covers about two-thirds of the health budget.

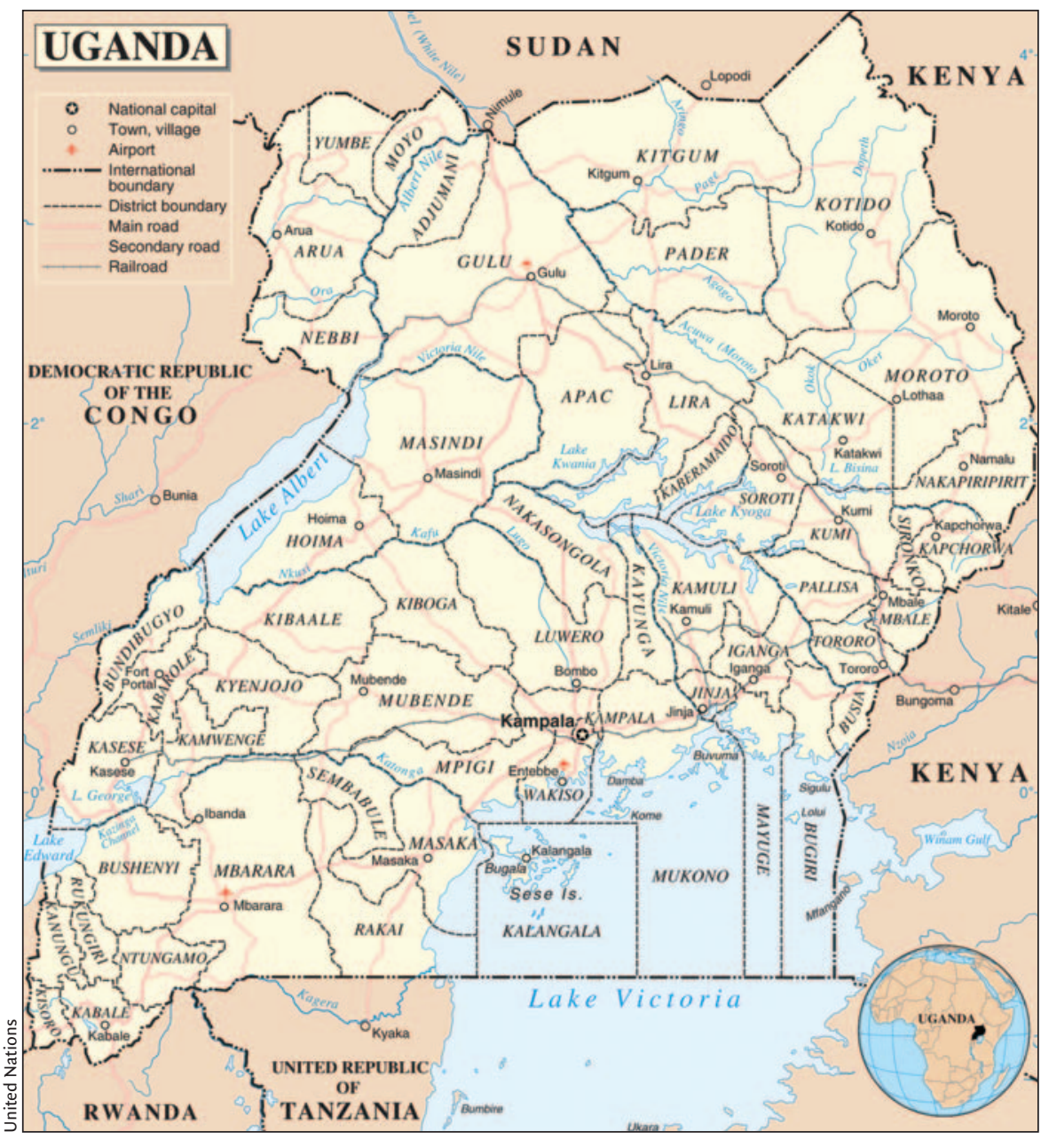

The former British protectorate of Uganda gained independence in 1962.

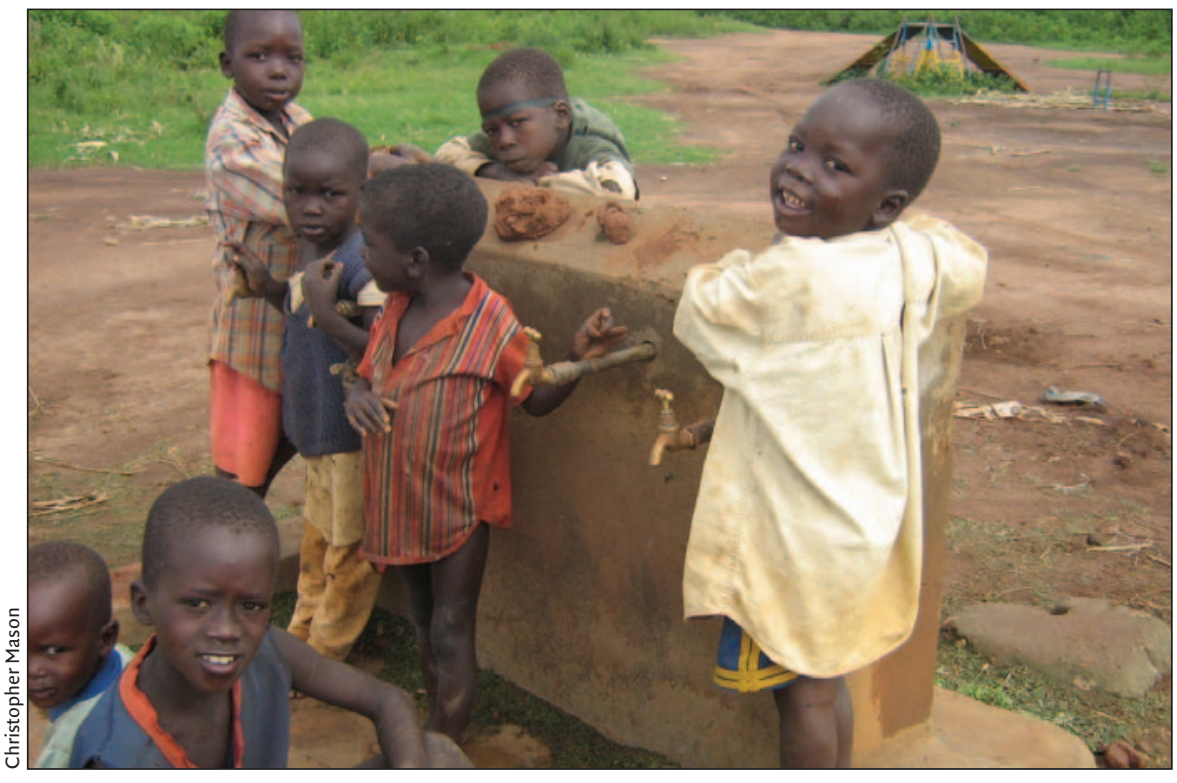

In a bid to persuade people to leave refugee camps and return to their homes, services like schools, health facilities, water and latrines are being shut down. Here children congregate around a water tap that has gone dry. 
The country's Ministry of Health projects that it would need about $16 \%$ of the government's budget to be spent on health for the system to function properly. Although spending once reached I0\%, it now fluctuates between 7 and $9 \%$.

"The health care system is underfunded," says Dr. Sam Okware,
Uganda's commissioner of Health Services. "Unless [r $6 \%$ is achieved], it will be hard for us to operate."

The system also faces instability from conflict in the north, sporadic flooding and other conditions (malaria, HIV/AIDs, malnutrition) common to countries throughout Africa, as well as

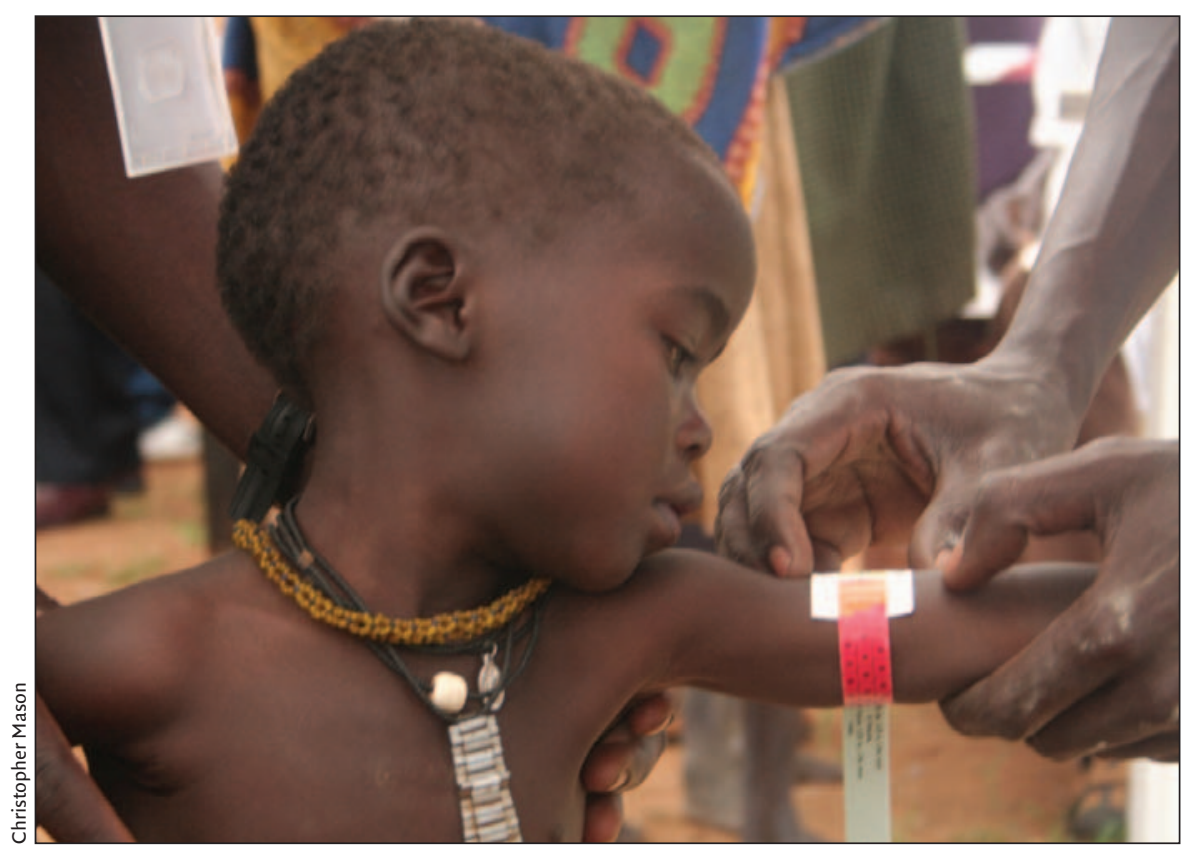

Aid workers use arm measurements to rate a child's malnutrition level in this isolated Kaabong region of northeastern Uganda.

\section{Box 1: Facts on Uganda}

\section{Demographics}

- Area: $236040 \mathrm{~km}^{2}$

- Population: 30262610

- Median age: 14.9 yr (14.8 male, 15 female)

Age structure: $50.2 \%$ under $15,47.6 \% 15-64$ yr, $2.2 \%$ over 64

- Birth rate: 48.12 births/1000 population

- Death rate: 12.64 deaths/1000 population

- Infant mortality rate: 67.22 deaths/1000 live births (70.92 male, 63.42 female)

- Life expectancy: 51.75 yr (50.78 male, 52.73 female)

\section{Economy}

- Gross domestic product per capita: US\$1900 (2006 estimate)

- Unemployment rate: not available

- Population below poverty line: 35\% (2001 estimate)

- Government revenues: US\$1.758 billion (2006 estimate)

- Government expenditures: US\$1.984 billion (2006 estimate)

- Public debt: $19.4 \%$ of gross domestic product (2006 estimate)

Health

- Total health expenditures as a percentage of gross domestic product: $7.6 \%$

- Government share of total health expenditure: $32.7 \%$

- Per capita total expenditure on health: US\$19

- Number of physicians: 2209 (2004); density per 1000 population: 0.08

- Number of nurses: 14 805; density: 0.55

Sources: Central Intelligence Agency World Factbook, World Health Organization. relatively unique disease challenges like a recent regional Ebola outbreak.

"In such times we have no choice but to use what is existing and replace it later when we can," Okware says.

When floods displaced hundreds of thousands in eastern Uganda in September, aid workers and local health officials struggled to contain malaria outbreaks and feared a cholera epidemic. In many villages, residents moved into schools and health centres because they were the only structures in the community with concrete floors that would allow people to escape the soggy muddy ground on which they would otherwise be forced to sleep.

This was the case in Ngariam, a small village about a ro-hour drive northeast of Kampala that had been established to protect area farmers from cattle raids conducted by tribes to the north. The community has a well-constructed health centre meant to give locals access to basic medicines and care.

At the height of the flooding, when so many were sick, it was full only with the belongings of those who had flocked to it for shelter because they didn't have the means to get to the next largest town, Io $\mathrm{km}$ away. The centre's shelves were empty, and had been that way for weeks.

"Here we have a situation where we have no medicine, when we're at risk of an outbreak of malaria, dysentery, cholera, or any of the viruses people can get during heavy flooding," said Ariko Thadeo, a clinical officer in charge of the Ngariam Health Centre.

The Ugandan Ministry of Health says it needs US\$4 per person per year to adequately deliver drugs to its citizens. Instead, they get about US\$1.67 per person per year.

There is typically a wide gap between health care services in the country's rural areas, such as Ngariam, and those in urban areas like the capital city Kampala. But an overall investment shortage leaves little resources for medicines, training and equipment.

According to the World Health Organization, the Ugandan government invests about US\$19 per capita on health, compared with Canada's US\$3037. Generally, the physical infrastructure of health centres and hospitals is adequate, but there's a lack of investment in serv- 
ices and personnel (Box I). There is, in particular, a dearth of trained professionals to treat patients, which forces everyone to seek novel solutions.

"Health care workers have to be innovative when they have so few resources," says Apollo Dalton Nyangasi, chairman of the Uganda Medical Workers Union.

Most doctors are trained at Kampala's Makerere University, I of 3 medical schools in the country. Students at Makerere attend 5 years of classes, followed by I year of full-time work at $\mathrm{Mu}$ lago Hospital. During that latter year, they are expected to toil 7 days a week for 12 months, all unpaid, which makes it extremely difficult for children from poor families to attend medical school.

Remarkably, despite the obstacles, funding shortfalls and challenges, there are success stories.

In the north, where rebels waged a 20-year civil war against the Ugandan government until peace was negotiated last year, immunization rates and overall health education among the population is very high.

This is mostly because many of the north's 4.5 million people lived in displaced persons' camps, some for parts or all of the 2 decade duration of the conflict. As such, international organizations had a centralized, captive audience to treat and educate on health concerns.

As people begin moving home, the Ugandan government has given $25 \%$ more funding to northern districts to help the region's health care system adjust to the changing environment.

Uganda is also often held up as an HIV/AIDS success story.

Having been $\mathrm{I}$ of the first countries to face an AIDS epidemic, it was also I of the first to respond with a coordinated campaign of education and testing.

Numbers vary, but it is generally held that Uganda's HIV/AIDS infections peaked in 199I, when about $15 \%$ of the population was infected. Today, less than $7 \%$ is said to be infected and there continue to be large-scale campaigns encouraging abstinence, condom use and faithfulness in marriage as ways to bring the number further down. Christopher Mason, Kampala, Uganda

DOI:Io.I503/cmaj.071795

\section{Mapping infectious}

\section{diseases in Africa}

M athematical modeling, by predicting the trajectory of infection, can become the next tool experts use to tackle infectious diseases that persist despite decades of effort to contain them, according to Canadian and African researchers attending a recent mathematical epidemiology conference in Kampala, Uganda.

The researchers hope their joint efforts to bridge mathematics and science will yield useful models that help policy-makers decide when and how to deploy resources (Figure I).

"Many diseases, such as malaria, have cyclical behaviour," explains Arvind Gupta, scientific director at British Columbia-based Mathematics of Information Technology and Complex Systems, which organized the meeting. "But often resources are needed at their most when malaria rates are at their lowest."

Often, when an infectious disease is most prevalent, it also has its lowest rate of new infections because the affected population is educated about the disease and resources are deployed. "It's when a disease dips that resources disappear and complacency sets in," Gupta says.

Modelling, or mathematical epidemi- ology, is meant to combat that tendency by showing policy-makers the correlation between infection rates, resource allocation and a disease's behaviour.

By doing that, researchers hope to avoid the wild fluctuations that often persist in infection rates, and instead focus on keeping the "R" value (rate of infection) at less than I at all times, meaning less than I person is infected with the disease for every I person who has it. If that can be accomplished, the disease begins a slow but steady march towards being eliminated.

Conference participants, who say that policy-makers do not fully recognize the role mathematical models can play in disease prevention, were optimistic that the groundwork has been laid for future collaborations that tap Canadian expertise in mathematical epidemiology and first-hand African knowledge of disease patterns.

"There are very good scientists here doing work in a resource-poor setting," says Abba Gumel, director of the University of Manitoba's Institute of Industrial Mathematics. "They don't have access to the resources we do in Canada. But we see that as a chance to build some real collaborations here because these are scientists who know the lay of the land and who to work with." Christopher Mason, Kampala, Uganda

DOI:I0.1503/cmaj.071749

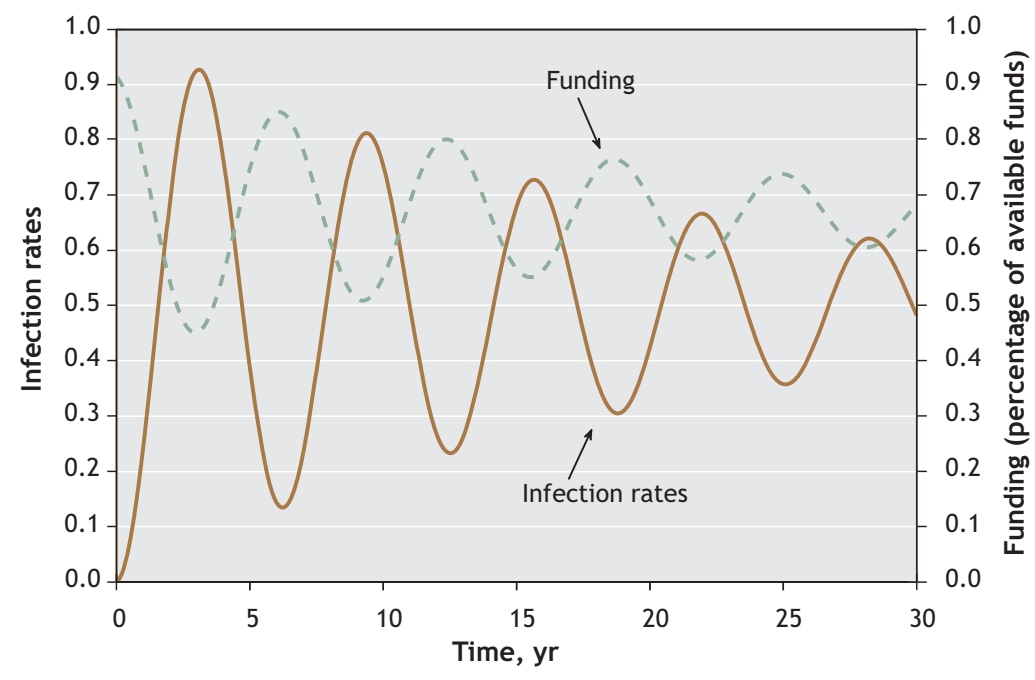

Figure 1: Researchers say that infectious diseases can be curbed through using of mathematical models demonstrating the correlation between infection rates, resource allocation and a disease's behaviours. 